\title{
Recommended immunization schedule for children and adolescents: Committee on Infectious Diseases of the Korean Pediatric Society, 2018
}

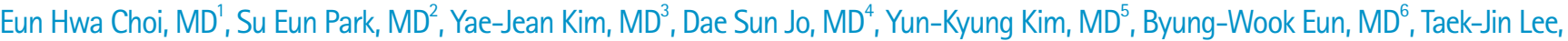

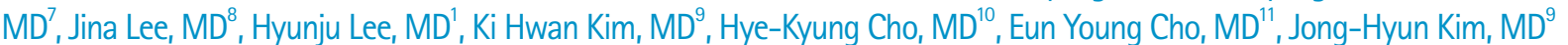 \\ Department of Pediatrics, ${ }^{2}$ Seoul National University College of Medicine, Seoul, ${ }^{2}$ School of Medicine, Pusan National University, Pusan, ${ }^{3}$ Sungkyunkwan University \\ School of Medicine, Suwon, ${ }^{4}$ Chonbuk National University Medical School, Jeonju, ${ }^{5}$ Korea University College of Medicine, Seoul, ${ }^{6}$ School of Medicine, Eulji University, \\ Daejeon, ${ }^{7} \mathrm{CHA}$ University School of Medicine, Pocheon, ${ }^{8}$ University of Ulsan College of Medicine, Ulsan, ${ }^{9}$ College of Medicine, The Catholic University of Korea, \\ Seoul, ${ }^{10}$ Gachon University College of Medicine, Incheon, ${ }^{11}$ Chungnam National University School of Medicine, Daejeon, Korea
}

The Committee on Infectious Diseases of the Korean Pediatric Society recommended immunization schedule for children and adolescents aged 18 years or younger in the 9th (2018) edition of Immunization guideline. This report provides the revised recommendations made by the committee and summarizes several changes from the 2015 guideline. National immunization program (NIP) launched a human papillomavirus (HPV) immunization for girls aged 12 years in 2016. NIP has also expanded age indication for inactivated influenza vaccine (IIV) to 12 years of age in the 2018-2019 season. Quadrivalent IIVs with a full dose $(0.5 \mathrm{~mL})$ are approved for all children of 6 months or older. Recommendations of live attenuated influenza vaccine were removed. For inactivated Japanese encephalitis vaccine, first 2 doses are considered as the primary series. Recommendations for use of newly introduced vaccines (diphtheria-tetanus-acellular pertussis/inactivated poliovirus/Haemophilus influenzae type b, 9-valent HPV, new varicella vaccine, new quadrivalent IIV, and attenuated oral typhoid vaccine) were added. Lastly, monitoring system for adverse events following immunization was updated. Other changes can be found in the 9th edition of Immunization guideline in detail.

Key words: Immunization schedule, Infant, Child, Adolescent, Korea

\section{Introduction}

The recommended immunization schedule for children and adolescents of 18 years or younger in Korea was revised on October 2018. The Committee on Infectious Diseases of the Korean Pediatric Society (KPS) released the 9th edition of Immunization guideline, ${ }^{1)}$ updated version of the previous 8th edition ${ }^{2)}$ published on 2015. This report focuses on the introduction of the revised recommendations on the childhood immunization schedule to pediatricians and other immunization providers. In addition, this report summarizes several changes in immunization practice in the Republic of Korea between 2015 and 2018.

National immunization program (NIP) introduced human papillomavirus (HPV) immunization for girls aged 12 years in 2016. A 2-dose series of either 2-valent or 4-valent HPV vaccine is recommended at six-month interval. NIP had also launched trivalent inactivated influenza vaccine (IIV) for infants and children of 6 to 59 months of age in the 2017-2018 season and expanded age indication to 12 years in the 2018-2019 season. Although children under 5 years of age are at high risk for serious complications of influenza, the committee agreed on the main purpose of age expansion to prevent the spread of influenza from school-
Corresponding author: Jong-Hyun Kim, MD Department of Pediatrics, St. Vincent's Hospital, College of Medicine, The Catholic University of Korea, 93 Jungbu-daero, Paldal-gu, Suwon 16247, Korea Tel: +82-31-249-8924

Fax: +82-31-257-9111

E-mail: jh00mn@catholic.ac.kr https://orcid.org/0000-0001-8641-7904

Received: 4 March, 2019

Accepted: 29 May, 2019

Copyright (C) 2019 by The Korean Pediatric Society

This is an open-access article distributed under the terms of the Creative Commons Attribution NonCommercial License (http://creativecommons.org/ licenses/by-nc/4.0/) which permits unrestricted noncommercial use, distribution, and reproduction in any medium, provided the original work is properly cited. 
Table 1. Recommended immunization schedule for children and adolescents: the Korean Pediatric Society, 2018

\begin{tabular}{|c|c|c|c|c|c|c|c|c|c|c|c|c|c|c|c|c|}
\hline Vaccine & $\begin{array}{l}\text { Acro- } \\
\text { nyms }\end{array}$ & Birth & $\begin{array}{l}0-34 \\
\text { days }\end{array}$ & $1 \mathrm{mo}$ & $2 \mathrm{mo}$ & $4 \mathrm{mo}$ & $6 \mathrm{mo}$ & $12 \mathrm{mo}$ & $15 \mathrm{mo}$ & $18 \mathrm{mo}$ & $\begin{array}{c}19-23 \\
\text { mo }\end{array}$ & $\begin{array}{c}24-35 \\
\text { mo }\end{array}$ & $4 \mathrm{yr}$ & $6 \mathrm{yr}$ & $11 \mathrm{yr}$ & $12 \mathrm{yr}$ \\
\hline Hepatitis $B^{a, \star)}$ & HepB & 1st & & 2nd & & & 3rd & & & & & & & & & \\
\hline $\mathrm{BCG}^{\mathrm{b})}$ & BCG & & 1 st & & & & & & & & & & & & & \\
\hline Diphtheria, tetanus, acellular pertussis ${ }^{\mathrm{c}, *)}$ & DTaP & & & & 1 st & 2nd & $3 r d$ & & \multicolumn{2}{|c|}{ 4th } & & & \multicolumn{2}{|c|}{ 5th } & & \\
\hline Inactivated poliovirus ${ }^{\mathrm{d}, \star)}$ & IPV & & & & $1 \mathrm{st}$ & 2nd & \multicolumn{4}{|c|}{$3 r d$} & & & \multicolumn{2}{|c|}{ 4th } & & \\
\hline Haemophilus influenzae type $b^{\mathrm{e}, *)}$ & Hib & & & & 1 st & 2nd & $3 r d$ & \multicolumn{2}{|c|}{ 4th } & & & & & & & \\
\hline Pneumococcal conjugate ${ }^{f)}$ & PCV & & & & 1 st & 2nd & 3rd & \multicolumn{2}{|c|}{4 th } & & & & & & & \\
\hline \multicolumn{17}{|l|}{ Rotavirus $^{g, t)}$} \\
\hline Rotarix & RV1 & & & & $1 \mathrm{st}$ & 2nd & & & & & & & & & & \\
\hline Rotateq & RV5 & & & & $1 s t$ & 2nd & 3rd & & & & & & & & & \\
\hline Influenza & IIV & & & & & & \multicolumn{10}{|c|}{ Annual } \\
\hline Hepatitis A & HepA & & & & & & & \multicolumn{5}{|c|}{1 st \& 2nd } & & & & \\
\hline Measles, mumps, rubella" & MMR & & & & & & & \multicolumn{2}{|c|}{ 1st } & & & & \multicolumn{2}{|c|}{ 2nd } & & \\
\hline Varicella $^{\mathrm{k})}$ & Var & & & & & & & \multicolumn{2}{|c|}{1 st } & & & & & & & \\
\hline \multicolumn{17}{|l|}{ Japanese encephalitis" } \\
\hline Inactivated & IJEV & & & & & & & \multicolumn{4}{|c|}{ 1st \& 2nd } & 3rd & & 4th & & 5th \\
\hline Live attenuated & LJEV & & & & & & & \multicolumn{4}{|c|}{$1 \mathrm{st}$} & 2nd & & & & \\
\hline Tetanus, diphtheria, acellular pertussis (Tdap) & Tdap & & & & & & & & & & & & & & \multicolumn{2}{|c|}{$1 s t$} \\
\hline Human papillomavirus ${ }^{\mathrm{n})}$ & HPV & & & & & & & & & & & & & & \multicolumn{2}{|c|}{$1 s t-2 n d(1 s t-3 r d)$} \\
\hline
\end{tabular}

HepB, hepatitis B vaccine; BCG, Bacille Calmette Guérin vaccine; DTaP, diphtheria-tetanus-acellular pertussis vaccine; IPV, inactivated poliovirus vaccine; Hib, Haemophilus influenzae type b vaccine; PCV, pneumococcus protein conjugate vaccine; RV, rotavirus vaccine; IIV, inactivated influenza vaccine; HepA, hepatitis A vaccine; MMR, measles-mumps-rubella vaccine; Var, varicella vaccine; IJEV, inactivated Japanese encephalitis vaccine; LJEV, live Japanese encephalitis vaccine; Tdap, adolescent adult type tetanus-diphtheria-acellular pertussis vaccine; HPV, human papillomavirus vaccine.

${ }^{*}$ Combination vaccines are available for HepB, DTaP, IPV, Hib vaccines. When administering combination vaccines, the minimum age for administration is the oldest age for any of the individual components. The minimum interval between doses is equal to the greatest interval of any of the individual components.

${ }^{\dagger}$ Rotavirus vaccine is an optional vaccine.

a) HepB: Administer monovalent HepB at 0,1, and 6 months of age; administer the third dose at least 8 weeks after the second dose and at least 16 weeks after the first dose, and no earlier than age 24 weeks. Administer the first dose according to the maternal hepatitis B surface antigen (HBsAg) status as follows: (a) If maternal HBsAg is positive, administer HepB and $0.5 \mathrm{~mL}$ of hepatitis B immune globulin (HBIG) within 12 hours of birth at different sites. (b) If maternal HBsAg status is unknown, administer HepB within 12 hours of birth and determine maternal HBsAg status as soon as possible. If maternal $\mathrm{HBsAg}$ is positive, also administer HBIG as soon as possible, but no later than age 7 days. (c) If maternal HBsAg is negative, administer HepB within 24 hours of birth.

${ }^{b} B C G$ : Administer BCG vaccine to neonates at birth through age 4 weeks. Infants over 3 months old require a tuberculin skin test before BCG vaccination.

c)DTaP: Administer a 5-dose series of DTaP vaccine at ages 2, 4, and 6 months as primary series, and at 15 through 18 months and 4 through 6 years as boosters.

dIIPV: Administer a 4-dose series of IPV at ages 2, 4, 6-18 months as primary series, and at 4 through 6 years as a booster.

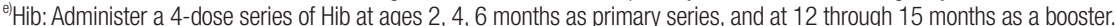

IPCV: Administer a 4-dose series of PCV at ages 2, 4, 6 months as primary series, and at 12 through 15 months as a booster.

${ }^{9} \mathrm{RV}$ : The first dose of any RV vaccines can be administered as early as at 6 weeks of age. The maximum age for the first dose in the series is 14 weeks 6 days; vaccination should not be initiated for infants aged 15 weeks 0 days or older. For Rotarix (GSK, Middlesex, UK), administer a 2-dose series at 2 and 4 months of age. For RotaTeq (MSD, NJ, USA), administer a 3-dose series at 2, 4, and 6 months of age. The minimum interval between any doses is 4 weeks, and the maximum age for the final dose in the series is 8 months 0 days.

h)IV: Administer the IIV annually to all children aged 6 months through 12 years anytime during an influenza season, preferably before the increase of incidence. Additionally, administer influenza vaccine to caregivers and family members of children aged 0 through 59 months, children and adolescents 5 years and older who have any underlying medical conditions at high risk for complications from influenza, the caregivers of high-risk children and adolescents, and all people who opt for the vaccine. Administer 2 doses (separated by at least 4 weeks) to children younger than 9 years who are receiving IV for the first time. Administer 1 dose to children and adolescents aged 9 years and older.

"HepA: Initiate the 2-dose HepA series at 12 through 23 months, and separate the 2 doses by 6 to 18 months in accordance with the products.

"MMR: Administer a 2-dose series of MMR at ages 12 through 15 months and at 4 through 6 years. Administer 1 dose of monovalent measles vaccine (or MMR) to infants aged 6 through 11 months when a measles outbreak occurs in the community. These children should be revaccinated with 2 doses of MMR, and the first dose should be administered at age 12 through 15 months and the second dose at age 4 through 6 years. The second dose may be administered before age 4 years with an interval of 4 weeks or more from the first dose in special situations.

${ }^{k}$ Var: Administer a single dose of Var to all children aged 12 through 15 months. The second dose of vaccine may be administered to children aged 12 months to 12 years who attend daycare centers, schools, or facilities where chicken pox is prevalent, provided at least 3 months have elapsed since the first dose.

IJEV: The first dose of any JEV, which is a 5-dose series of IJEV or a 2-dose series of LJEV, may be administered to children aged 12 through 23 months. If IJEV is used, administer 2-dose primary series at an interval of 7 to 30 days and administer booster doses at 12 months after the second dose, at ages 6 and 12 years, respectively. If LJEV is used, administer the second dose at least 12 months after the first dose.

${ }^{m}$ Iddap: Administer 1 dose of Tdap to adolescents aged 11 through 12 years who are fully immunized with the DTaP. Administer tetanus and diphtheria toxoid (Td) as boosters every 10 years thereafter.

n)HPV: Administer a 2-dose series of either Cervarix (GSK, Rixensart, Belgium) or Gardasil (MSD) at 6-month interval for all girls aged 11-12 years. Administer a 3-dose series of HPV for girls with immunocompromising conditions or those who are 15 years (14 years for Gardasil) or older at initial vaccination, Cervarix with 0-, 1-, and 6-month schedule or Gardasil/Gardasil9 with 0-, 2-, and 6-month schedule. 
Table 2. Catch-up immunization schedule for persons aged 4 months through 18 years who start late or who are more than 1 month behind: the Korean Pediatric Society, 2018*

\begin{tabular}{|c|c|c|c|c|c|}
\hline \multirow{2}{*}{ Vaccine } & \multirow{2}{*}{$\begin{array}{l}\text { Minimum age } \\
\text { for dose } 1\end{array}$} & \multicolumn{4}{|c|}{ Minimal interval between doses } \\
\hline & & Dose 1 to dose 2 & Dose 2 to dose 3 & Dose 3 to dose 4 & Dose 4 to dose 5 \\
\hline \multicolumn{6}{|c|}{ Children aged 4 months through 6 years } \\
\hline Hepatitis $B^{\text {a) }}$ & Birth & 4 Weeks & $\begin{array}{l}8 \text { Weeks (at least } 16 \text { weeks after } 1 \text { st dose) } \\
\text { Minimum age for the } 3 r d \text { dose is } 24 \text { weeks }\end{array}$ & & \\
\hline $\begin{array}{l}\text { Diptheria, tetanus, acellular } \\
\text { pertussis }(\mathrm{DTaP})^{\mathrm{b})}\end{array}$ & 6 Weeks & 4 Weeks & 4 Weeks & 6 Months & 6 Months $^{2)}$ \\
\hline Inactivated poliovirus ${ }^{c)}$ & 6 Weeks & 4 Weeks & 4 Weeks & 6 Months $^{3)}$ & \\
\hline $\begin{array}{l}\text { Haemophilus influenzae } \\
\text { type } b^{d)}\end{array}$ & 6 Weeks & $\begin{array}{l}4 \text { Weeks: if } 1 \text { st dose was administered } \\
\text { before the 1st birthday } \\
8 \text { Weeks (as final dose): if 1st dose was } \\
\text { administered at age } 12 \text { through } 14 \\
\text { months } \\
\text { No further doses needed: if } 1 \text { st dose was } \\
\text { administered at age } 15 \text { months or older }\end{array}$ & $\begin{array}{l}4 \text { Weeks }{ }^{4)} \text { : if current age is younger than } 12 \\
\text { months and } 1 \text { st dose was administered at } \\
\text { younger than age } 7 \text { months } \\
8 \text { Weeks and age } 12 \text { through } 59 \text { months (as } \\
\text { final dose): if current age is younger than } \\
12 \text { months and } 1 \text { st dose was administered } \\
\text { at age } 7 \text { through } 11 \text { months } \\
8 \text { Weeks and age } 12 \text { through } 59 \text { months (as } \\
\text { final dose): if current age is } 12 \text { through } 59 \\
\text { months and } 1 \text { st dose was administered } \\
\text { before the } 1 \text { st birthday, and second dose } \\
\text { administered at younger than } 15 \text { months } \\
\text { No further doses needed: if previous dose } \\
\text { was administered at age } 15 \text { months or } \\
\text { older }\end{array}$ & $\begin{array}{l}8 \text { Weeks (as final dose): This } \\
\text { dose only necessary for } \\
\text { children age } 12 \text { through } \\
59 \text { months who received } \\
3 \text { doses before the } 1 \text { st } \\
\text { birthday }\end{array}$ & \\
\hline Pneumococcal conjugate ${ }^{e)}$ & 6 Weeks & $\begin{array}{l}4 \text { Weeks: if 1st dose administered before } \\
\text { the 1st birthday } \\
8 \text { Weeks (as final dose for healthy children): } \\
\text { if } 1 \text { st dose was administered at age } 12 \\
\text { through } 23 \text { months } \\
8 \text { Weeks (as final dose for healthy children): } \\
\text { if } 1 \text { st dose of PCV10 administered at age } \\
24 \text { months or older } \\
\text { No further doses needed for healthy children: } \\
\text { if } 1 \text { st dose of PCV13 administered at age } \\
24 \text { months or older }\end{array}$ & $\begin{array}{l}4 \text { Weeks: if current age is younger than } 12 \\
\text { months and previous dose given at }<7 \\
\text { months old } \\
8 \text { Weeks (as final dose for healthy children): } \\
\text { if previous dose given between } 7 \text { through } \\
11 \text { months (wait until at least } 12 \text { months } \\
\text { old) } \\
8 \text { Weeks (as final dose for healthy children): } \\
\text { if current age is } 12 \text { months or older and } \\
\text { at least } 1 \text { dose was given before age } 12 \\
\text { months } \\
\text { No further doses needed for healthy children: } \\
\text { if previous dose administered at age } 24 \\
\text { months or older. }\end{array}$ & $\begin{array}{l}8 \text { Weeks (as final dose): This } \\
\text { dose only necessary for } \\
\text { children aged } 12 \text { through } \\
59 \text { months who received } \\
3 \text { doses before age } 12 \\
\text { months or for children at } \\
\text { high risk who received } 3 \\
\text { doses at any age }\end{array}$ & \\
\hline Rotavirus ${ }^{\dagger}$ & 6 Weeks & 4 Weeks & 4 Weeks & & \\
\hline Hepatitis $A^{g)}$ & 12 Months & 6 Months & & & \\
\hline$M_{M} R^{h)}$ & 12 Months & 4 Weeks & & & \\
\hline Varicellai & 12 Months & 3 Months & & & \\
\hline Japanese encephalitis" & 12 Months & $\begin{array}{l}7 \text { Days: inactivated vaccine } \\
12 \text { Months (as final dose): live vaccine }\end{array}$ & 6 Months: inactivated vaccine & $\begin{array}{l}2 \text { Years: inactivated vac- } \\
\text { cine }\end{array}$ & $\begin{array}{l}5 \text { Years: inactivated } \\
\text { vaccine }\end{array}$ \\
\hline \multicolumn{6}{|c|}{ Children and adolescents aged 7 through 18 years } \\
\hline Hepatitis $B^{\text {a) }}$ & NA & 4 Weeks & $\begin{array}{l}8 \text { Weeks and at least } 16 \text { weeks after 1st } \\
\text { dose }^{1)}\end{array}$ & & \\
\hline Inactivated poliovirus ${ }^{c)}$ & NA & 4 Weeks & 4 Weeks & 6 Months & \\
\hline Hepatitis $A^{g)}$ & NA & 6 Months & & & \\
\hline$M M R^{h)}$ & NA & 4 Weeks & & & \\
\hline Varicella” & NA & $\begin{array}{l}3 \text { Months: if younger than age } 13 \text { years } \\
4 \text { Weeks: if age } 13 \text { years or older }\end{array}$ & & & \\
\hline Japanese encephalitis & NA & $\begin{array}{l}7 \text { Days: inactivated vaccine } \\
12 \text { Months (as final dose): live vaccine }\end{array}$ & 6 Months: inactivated vaccine & 2 Years: inactivated vaccine & \\
\hline $\begin{array}{l}\text { Tetanus, diphtheria, } \\
\text { acellular pertussis (Tdap)/ } \\
\text { Tetanus, diphtheria }(\mathrm{Td})^{\mathrm{k})}\end{array}$ & 7 Years & 4 Weeks & $\begin{array}{l}4 \text { Weeks: if } 1 \text { st dose of DTaP was administered } \\
\text { before age } 12 \text { months } \\
6 \text { Months: if } 1 \text { st dose of DTaP was admini- } \\
\text { stered at or after age } 12 \text { months }\end{array}$ & $\begin{array}{l}6 \text { Months: if } 1 \text { st dose of } \\
\text { DTaP was administered } \\
\text { before age } 12 \text { months } \\
10 \text { Years: if } 1 \text { st dose of DTaP } \\
\text { was administered at or } \\
\text { after age } 12 \text { months }\end{array}$ & \\
\hline Human papillomavirus" & 9 Years & Routine dosing intervals are recommended & Routine dosing intervals are recommended & & \\
\hline
\end{tabular}


PCV10, pneumococcal conjugate 10-valent vaccine; PCV13, pneumococcal conjugate 13-valent vaccine.

${ }^{*}$ A vaccine series does not need to be restarted, regardless of the time that has elapsed between doses. For additional information regarding each vaccine, vaccination providers should refer to appropriate part of the Korean Pediatric Society Immunization Guideline or the insert paper for each vaccine.

a) Hepatitis B vaccine: Unvaccinated children or adolescents should complete a 3-dose series. Minimum age at the third dose is 24 weeks.

${ }^{b}$ Diphtheria, tetanus toxoid, and acellular pertussis (DTaP) vaccine: The fifth dose of the DTaP vaccine is not necessary if the fourth dose was administered at age 4 years or older.

${ }^{c}$ Inactivated poliovirus vaccine (IPV): In the first 6 months of life, minimum age and minimum intervals are only recommended if the person is at risk of imminent exposure to circulating poliovirus. The final dose in the series should be administered on or after the fourth birthday and at least 6 months after the previous dose. The fourth dose is not necessary if the third dose was administered at age 4 years or older and at least 6 months after the previous dose. If both the oral poliovirus vaccine (OPV) and IPV were administered as part of a series, a total of 4 doses should be administered, regardless of the child's current age.

${ }^{d)}$ Haemophilus influenzae type b (Hib) vaccine: For unvaccinated children aged 15 through 59 months, administer only 1 dose. Hib vaccine is not recommended for healthy children 5 years or older.

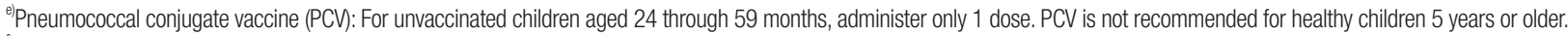

IRotavirus (RV) vaccine: The first dose of any RV vaccines can be administered as early as at 6 weeks of age. According to the product, administer a 2-dose (Rotarix, GSK, Middlesex, UK) or 3-dose series (Rotateq, MSD, NJ, USA). The minimum interval between any doses is 4 weeks, the maximum age for the first dose in the series is 14 weeks 6 days, and the maximum age for the final dose in series is 8 months 0 days.

${ }^{9}$ Hepatitis A vaccine: Children should receive a second dose 6 to 18 months after the first dose.

") Measles, mumps, rubella (MMR) vaccine: Administer the second dose at age 4 through 6 years. However, the second dose may be administered at least 4 weeks after the first dose in special situations.

"Varicella vaccine: For children aged less than 13 years without evidence of immunity for varicella zoster, administer only 1 dose. For adolescents aged 13 years or older without evidence of immunity for varicella zoster, administer 2 doses with a 4- to 8-week interval. The second dose of vaccine may be administered to children aged 12 months to 12 years who attend facilities where chicken pox is prevalent, provided at least 3 months have elapsed since the first dose.

IJapanese encephalitis vaccine (JEV): If the third dose of inactivated JEV was administered at age 4 through 9 years, the fourth dose may be administered as a final dose at age 12 years. If the third dose of inactivated JEV was administered at age 10 years or more, an additional dose is not necessary. If live attenuated JEV is used, administer the second dose at least 12 months after the first dose.

${ }^{\mathrm{k}}$ Tetanus and diphtheria toxoid and acellular pertussis (Tdap)/tetanus and diphtheria toxoid (Td) vaccine: Persons aged 7 years and older who are not fully immunized with DTaP vaccine should receive Tdap vaccine as 1 dose (preferably the first) in the catch-up series and if additional doses are needed, use the Td vaccine.

"Human papillomavirus (HPV) vaccine: Administer the 2nd dose as a final dose for girls who received 1st dose at the age younger than 15 years (14 years for Gardasil [MSD]) at minimal interval of 5 months (6 months for Gardasil). For girls with immunocompromising conditions or those who are 15 years (14 years for Gardasil) or older at initial vaccination, administer the 2nd dose 1 month after the 1st dose of Cervarix (GSK, Rixensart, Belgium) and 2 months after the 1st dose of Gardasi/Gardasil9. Administer the 3rd dose for all HPV vaccines 5 months after the 1 st dose. Minimal intervals between the 1st-2nd, 2nd-3rd, and 1st-3rd doses are 4 weeks, 12 weeks, and 5 months, respectively.

aged children to the community. Other changes in influenza vaccine are as follows: quadrivalent IIV of full dose $(0.5 \mathrm{~mL})$ may be used for all children of 6 months or older. Recommendations of live attenuated vaccine were removed because it is no longer available for use in Korea. For inactivated Japanese encephalitis vaccine, first 2 doses are considered as the primary series and third dose is a booster dose. Recommendations for the use of newly introduced vaccines were added. Diphtheria-tetanus-acellular pertussis/inactivated poliovirus/Haemophilus influenzae type b vaccine (Pentaxim, Sanofi Pasteur SA., Lyon, France), 9-valent HPV vaccine (Gardasil 9, Merck \& Co., Inc., Whitehouse Station, NJ, USA), new varicella vaccine (SKY Varicella, SK Bioscience, Andong, Korea), inactivated quadrivalent influenza vaccines (GC FLU Quadrivalent, GC Pharma, Yongin, Korea; SKY Cellflu Quadrivalent, SK Bioscience; FluarixTetra, GlaxoSmithKline, Middlesex, UK; and Vaxigrip Tetra, Sanofi-Pasteur SA) were introduced. Lastly, monitoring system for adverse events following immunization (AEFI) was updated. Along with a surveillance system for AEFI that has been maintained for NIP vaccines by Korea Centers for Disease Control and Prevention (KCDC), Korea Institute of Drug Safety (KIDS) collects AEFI as well. By sharing the data between KCDC and KIDS, a better comprehensive safety surveillance system is under construction. More details on recommendations and changes can be found in the 9th edition of Immunization guideline.

\section{Recommended immunization schedule}

Table 1 shows the recommended immunization schedule for children and adolescents aged 0 through 18 years. These recommendations must be read with the following notes at the bottom of the table. As previously mentioned, age expansion of IIV to 12 years and a 2-dose series of HPV vaccine are the main changes in the current recommended schedule. It is important to note that the committee decided not to recommend the meningococcal quadrivalent conjugate vaccine for healthy children who are not at increased risk of meningococcal disease, based on the epidemiology of invasive meningococcal diseases in Korea. ${ }^{3)}$ Pediatricians and other immunization providers should always ensure that they are following the most up-to-date schedules, which are available from each chapter of the 9th Immunization guideline 2018, newsletters including the important updates on the recommendations, and the KPS website at http://www.pediatrics.or.kr.

\section{Catch-up immunization schedule}

For those who start vaccine late or are behind the schedule, catchup immunization schedule is indicated in Table 2. For children and adolescents whose vaccination has been delayed for more than 1 month, the catch-up immunization schedule should be referred to. The catch-up schedule consists of 2 parts; one for infants and preschoolers aged 0 through 6 years, the other for children and 
adolescents from 7 to 18 years of age.

\section{Conclusion}

The current KPS recommendation of immunization proposes that all children and adolescents residing in or planning to reside in Korea should be immunized according to the schedules provided in this report. Pediatricians and other vaccine providers should be aware of these updated recommendations and advice parents and caregivers on proper immunization practices based on these updated guidelines.

\section{Conflict of interest}

No potential conflict of interest relevant to this article was reported.

\section{References}

1. The Korean Pediatric Society. Recommended immunization schedule for children and adolescents. In: Kim JH, editor. Immunization guideline. 9th ed. Seoul: The Korean Pediatric Society, 2018:2-5.

2. The Korean Pediatric Society. Recommended immunization schedule for children and adolescents. In: Kim KH, editor. Immunization guideline. 8th ed. Seoul: The Korean Pediatric Society, 2015:2-5.

3. Kim JH. Infectious diseases in children and adolescents in the Republic of Korea; Past \& recent status. Korean J Pediatr 2011;54:489-500. 